\title{
Sponge digestive system diversity and evolution: filter feeding to carnivory
}

\author{
Nelly Godefroy' • Emilie Le Goff' ${ }^{\prime}$ Camille Martinand-Mari' $•$ Khalid Belkhir ${ }^{1} \cdot$ Jean Vacelet ${ }^{2}$ • \\ Stephen Baghdiguian ${ }^{1}$
}

\begin{abstract}
Sponges are an ancient basal life form, so understanding their evolution is key to understanding all metazoan evolution. Sponges have very unusual feeding mechanisms, with an intricate network of progressively optimized filtration units: from the simple choanocyte lining of a central cavity, or spongocoel, to more complex chambers and canals. Furthermore, in a single evolutionary event, a group of sponges transitioned to carnivory. This major evolutionary transition involved replacing the filter-feeding apparatus with mobile phagocytic cells that migrate collectively towards the trapped prey. Here, we focus on the diversity and evolution of sponge nutrition systems and the amazing adaptation to carnivory.
\end{abstract}

Keywords Sponge $\cdot$ Porifera $\cdot$ Evolution $\cdot$ Choanocyte $\cdot$ Filtration $\cdot$ Carnivory

\section{Introduction}

Sponges, or Porifera, are traditionally considered as one of the key groups for understanding basal metazoan evolution. The Porifera are a rich taxon of 8000 to 9000 described species, currently divided into four monophyletic classes: Demospongiae, Calcarea, Homoscleromorpha and, the most differentiated form, the Hexactinellida. Despite the prevalent view of sponges as Bsimple^ animals, they have very sophisticated feeding mechanisms involving the whole body and including a network of water filtration units, known as the aquiferous system. Studying the aquiferous system morphology of sponge classes, subclasses, orders and suborders will show us a very clear and interesting story of the successive modifications. Thus, the system has various degrees of complexity from the simplest

$\approx$ Jean Vacelet jean.vacelet@imbe.fr

* Stephen Baghdiguian stephen.baghdiguian@umontpellier.fr

1 ISEM, CNRS, EPHE, IRD, Univ Montpellier, Montpellier, France

2 IMBE, CNRS, IRD, Station Marine d'Endoume, Aix Marseille Univ, Univ Avignon, 13007 Marseille, France asconoid organization to the most complex leuconoid and solenoid filtration units (Fig. 1a). The great anatomical diversity of the five sponge organization plans raises a number of questions concerning which are the most ancestral and which are the most efficient in terms of filtration. But whatever the evolutionary history of the classic filtering sponge aquiferous system, these different architectures, which aimed at optimizing food intake by increasing the exchange surfaces of the filtration system with the medium, never translated into a radical change in the general organization of the body plan, unlike that which occurred in carnivorous sponges (see below). In contrast to the diversity of Calcarea that possess the five types of body plan, in Hexactinellida, only leuconoids and syconoids are observed. All Homoscleromorpha are leuconoids, with a possible exception of Oscarella filipoi where a sylleibid system has been described in Perez and Ruiz (2018) and all the extant Demospongiae are leuconoids (Fig. 1c). It is likely that the evolution in the class Calcarea (sponges characterized by calcareous spicules) occurred by the complexification of the asconoid type into syconoid, sylleibid, leuconoid, or solenoid organization (Cavalcanti and Klautau 2011). The same scenario can be considered for the other three sponge classes with a secondary loss of asconoid, syconoid, sylleibid and/or solenoid forms. However, to date, there are no fossil remains or other evidence available to strengthen this hypothesis. 

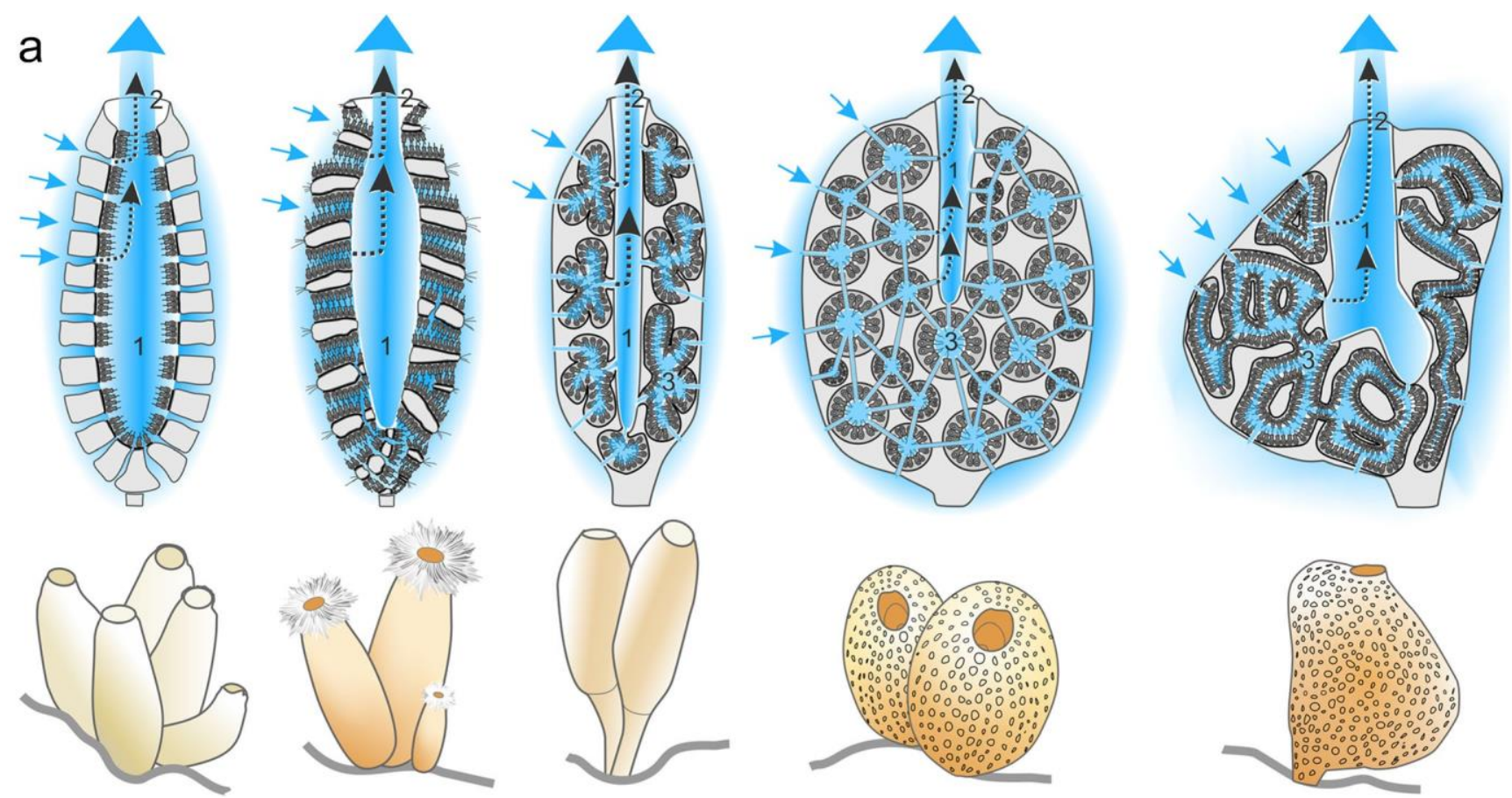

Asconoid

Syconoid

Sylleibid

Leuconoid

Solenoid
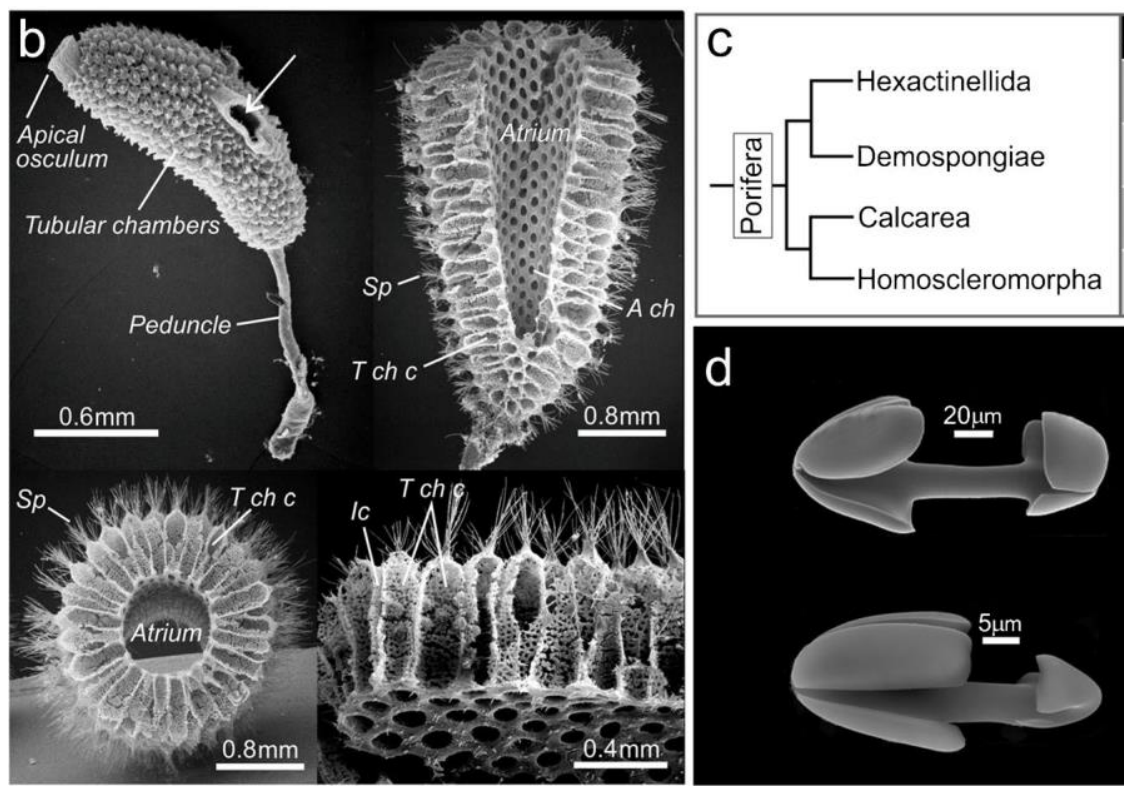

\begin{tabular}{l|l|l|l|l|}
\hline Asconoid & Syconoid & Sylleibid & Leuconoid & Solenoid
\end{tabular}

Fig. I Sponge nutrition system anatomy. a Schematic representation of the five sponge morphotypes. Arrows indicate the direction of the seawater flow into the spongocoel or atrium (1) and out through the oscule exhalant pore (2). In the more complex types, the water initially passes through a choanocyte chamber (3). Note numbers are deliberately faint to preserve the realism of the graphics. BGraphic design: (OLaurence Meslin - CNRS 2018.^ b Scanning electron microscope view of Sycon sycandra. The upperleft shows a whole specimen. The other micrographs show different sections obtained by cryo-fracture after double fixation in glutaraldehyde and osmium followed by ultra-fast congelation in liquid nitrogen and metallization. Micrographs illustrate the morphological organization of the syconoid system; sp, spicules; A ch, atrium chamber; T ch c, tubular choanocyte chamber; ic, inhalant canals; in left upper panel,

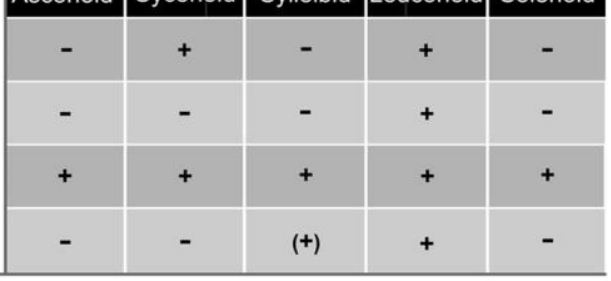

Filter/Feeder

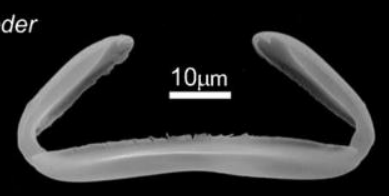

Carnivorous

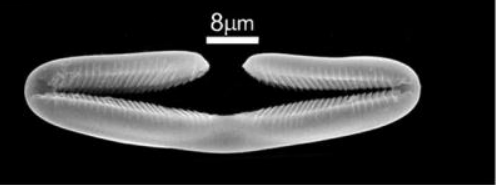

the arrow shows an additional exhalant orifice. $\mathrm{c}$ Phylogeny of the four classes of sponges in relation to the presence + or absence - of the five sponge morphotypes, $(+)$ means that sylleibid organization was found only in one species in Homoscleromorpha. d Scanning electron microscopy of representative spicules of filter/feeder sponges (upperpanels) and carnivorous sponges (lowerpanels).Leftupperpanel:Palmate anisochela from Mycale (Oxymycale klausjanusorum, Van Soest, 2018), Mycalidae (filtering sponges) (courtesy of Rob VanSoest). Left lower panel:Palmate anisochela from an undescribed Asbestopluma, Cladorhizidae (carnivorous). Right upper panel: Placochela from Guitarra solorzanoi Cristobo, 1998, Guitarridae (filtering sponges) (courtesy of Javier Cristobo). Right lower panel: Placochela from Euchelipluma pristina Topsent, 1909, Cladorhizidae (carnivorous) 


\section{Anatomical generalities}

The simplest of the five extant sponge plans, the asconoid form, is found only in the smallest calcareous sponges such as Ascaltis, Clathrina and Leucosolenia. The asconoids are characterized by inhalant pores (or ostia) directly connected to the large central spongocoel cavity, which is lined with a monolayer of flagellated choanocytes. In syconoids, the choanocytes line a multitude of small radial channels rather than directly lining the spongocoel (Fig. 1b). This organization plan was an evolutionary advance because it increases the contact surface area between the cells of the animal and the surrounding water, allowing greater absorption of food and increased body size. The syconoid body plan is found among Calcarea, for instance, in the genera Grantessa, Sycon and Sycettusa. In the third form, the sylleibids, the choanocyte chambers are radially arranged around invaginations of the atrial cavity. The sylleibid body plan is found in Calcarea Leucilla, Leucandra and Jenkina genera. In the fourth form, the leuconoids, which is the only form present in all four classes of sponges, the choanocytes are collected in elongated or spherical choanocyte chambers. These chambers are not linked to each other, but rather they communicate with the spongocoel and ostia through channels. This organization has the effect of slowing down the inward flow, which facilitates the filtration of the organic matter. This form is predominant in large calcareous sponges and essentially all of the demosponges, hexactinellids and homoscleromorphs are leuconoid. In the fifth and final filtering sponge body plan, solenoids, the filtration system is formed by anastomosing tubes lined with choanocytes on the inner side and the atrium lacks choanoderm. The solenoid body plan was only recently described, in 2011, in calcareous sponges of the genus Leucascus (Cavalcanti and Klautau 2011) (Fig. 1c). Evolution of the choanocyte lining and the choanocyte chamber thus represented an efficiency drive that improved the nutrition process at the cellular and tissue levels, respectively. This efficiency drive, both in volume filtration, particle of organic matter retention and nutrient transfer, is most pronounced in the Hexactinellida, which are specially adapted to the deep sea. In these sponges, the leuconoid flagellar chambers, composed of a thin layer of anucleate ch oa nom ere s ( o r b ra nc hed c hoa no cyt es), a re complemented by a single, multinucleate syncytium ramifying throughout the sponge. This trabecular reticulum fulfills diverse functions, such as food transport in the whole animal and coordination of the filtering activity in the absence of a nervous system (Leys et al. 2007). Another efficiency adaptation that was developed to a greater or lesser degree in different types of sponge body plans is the formation of the mesohyl space that is made of a gelatinous extracellular matrix between the pinacoderm and choanoderm. The number of symbiotic bacteria increases with the density of this structure to maximize digestion (see the BInvolvement of the microbiota in the carnivorous $\operatorname{diet}^{\wedge}$ section).

\section{Nutrition/digestion in filtering sponges}

In filtering sponges, nutritive particles are mostly trapped by flanges at the apical pole of choanocytes. Food particles are intracellularly digested by lysosomal acid phosphatases, as well as by alpha glucosidases, beta hexosaminidases and cathepsin D (Hahn-Keser and Stockem 1998). Cysteine proteinases like cathepsin L were biochemically implicated in the digestive process of Geodia cydonium also (Krasko et al. 1997). After intravacuolar digestion, the nutritive vacuoles are exocytosed from choanocytes and delivered topinacocytes and archeocytes, which pass them on to another cell type via the mesohyl space. Proof of this came when Ephydatia fluviatilis were fed latex beads and the beads appeared in choanocytes after $10 \mathrm{~min}$ of incubation, in exopinacocytes after $20 \mathrm{~min}$, in mesohyl and endopinacocytes after $40 \mathrm{~min}$ and finally in some archeocytes after up to $12 \mathrm{~h}$ (Willenz 1980). Fluid pinocytosis is a type of endocytosis allowing the capture of macromolecules and solutes in small vesicles that are redirected and incorporated into lysosomes. This kind of endocytosis has been observed for beta glycogen and iron saccharate transport in the leuconoidDemospongiaeSuberites massa (Diaz 1979). Many questions relating to the precise kinetics and transfer routes of filtered food still need to be studied. At this stage, however, it is reasonable to propose the following scenario. Some of the choanocytes that have captured nutritive micro-particles transfer food to all the other cells via archeocytes, while a distinct subpopulation of the choanocytes transdifferentiate into additional archeocytes with regenerative potential. Thus, the diet would maintain the energetic needs of the sponge while ensuring its growth by forming new choanocyte chambers and all that without changing the global morphotype of the animal throughout its life cycle. Note that growth is limited as much by the competition from other species in the ecosystem as by the nature and abundance of the nutriments in the medium.

\section{Nutrition and digestion in carnivorous species: data from Lycopodina hypogea}

The discovery of L. hypogea (Demospongiae), initially called Asbestopluma hypogea and its carnivorous behavior by Vacelet and Boury-Esnault in 1995 completely changed our vision of sponge aquiferous system evolution. L. hypogea is not unique in this respect and indeed over a hundred carnivorous species have been identified exclusively in Demospongiae and most of them from deep waters. 
L. hypogea and the related species Lycopodina occidentalis are currently the only carnivorous sponges to be accessible to experimentation in the laboratory but only L. hypogea can be harvested by scuba divers (Vacelet and Duport 2004; Riesgo et al. 2007; Martinand-Mari et al. 2012). The study of Lycopodina revealed that these carnivorous sponges were not even sponges in the classical sense as they no longer meet the phylum definition of sponges of Bergquist (1978) as Ba sedentary, filter-feeding metazoan, which utilizes a single layer of flagellated cells (choanocytes) to pump a unidirectional water current through its body.^ These species have developed a design that is unique among metazoans that enables them to feed on macro-prey by phagocytosis (Fig. 2a-c). The phagocytic cells act independently Bin their own interest ${ }^{\wedge}$ completely without relying on the organism's macro scale digestive cavity or specialized glands (Vacelet and Duport 2004). The independent acquisition of a carnivorous diet in various flowering plants is also a spectacular example of adaptation and convergent evolution. However for plants, liveprey is only a supplementary food that is accommodated without a complete change in the nutrition system. For example, all the leaves of the insectivorous pitcher plant Cephalotus follicularis are photosynthetic but only some leaves are carnivorous (Fukushima et al. 2017). Conversely to the situation in plants, the reorganization of the nutrition/digestion system in carnivorous sponges was accompanied by major morphofunctional modifications that led to a strictly carnivorous diet (Vacelet and Duport 2004; Martinand-Mari et al. 2012). In L. hypogea, fasting animals are characterized by the presence of many highly elongated filaments that play a decisive role in the capture of prey. After capture of prey, which are usually small crustaceans under $8 \mathrm{~mm}$ long and throughout the digestive process, these filaments regress rapidly before reforming, just as quickly, during the next fasting period. The average duration of an experimentally established cycle is approximately 9 days. These morphogenetic transformations are directly linked to an extremely dynamic cell turnover that involves coordination between programmed cell death (apoptosis, autophagy), proliferation and cell migration (MartinandMari et al. 2012). L. hypogea, like many other carnivorous sponges, is attached to its substrate by a peduncle. At the base of the peduncle, there is a niche of stem cells that contributes to the overall cellular renewal of the body. When prey is ingested, there is a massive proliferation of these cells as shown by BrdU/EdU incorporation (Martinand-Mari et al. 2012). Sponge stem cells proliferate and then differentiate into digestive cells that migrate along the central needle-like spicules of the peduncle to the prey at around $0.2 \mathrm{~mm}$ per hour (see movie in supplementary data of Martinand-Mari etal.2012) at least in L. hypogea or other small species such as L. occidentalis. Indeed, it is difficult to assume that such a mechanism can occur in carnivorous sponges sometimes surpassing the meter of length. The ensuing digestion ensures the energy requirements of the animal including for its reproduction. Although it has not yet been demonstrated, we can hypothesize that some of these stem cells (probably archeocytes that are described as totipotent cells in most studied sponges) (Funayama 2013) could then transdifferentiate to allow the regeneration of filaments, while others among them could act as a pool of Bmemory cells, ${ }^{\wedge}$ returning to the peduncle base in wait for new prey. Finally, the hard skeletal parts of the prey, such as the chitinous exoskeleton of the crustaceans, are possibly digested by endogenous chitinase (Table 1), probably in synergie with chitinase of bacterial origin (see Fig. 2e and Vacelet and Duport 2004; Dupont et al. 2013, 2014), or partly rejected for the hardest parts. Overall then, we see above that the complexity of regulation of cell dynamics and turnover in L. hypogea rivals that of bilateral metazoans (Martinand-Mari et al. 2012).

\section{Spicule diversity in filtering and carnivorous sponges}

As explained above, the strategy for nutrition and digestion is completely different in filter feeding and carnivorous species. As well as developing mobile phagocytic cells (and losing the ability to filter feed), carnivorous sponges also needed to developfurther secondary adaptations toefficiently capture large prey. The carnivores achieved this with an erect body shape that incorporates long filaments. In some genera, e.g., Chondrocladia, the filaments have specialized spheres at their extremities that play the role of a float. In all the carnivores, the filaments have a regular lining of small siliceous hook-like spicules, generally under $100 \mu \mathrm{m}$ long called microscleres (e.g., anisochelae, placochelae) that make a Velcro-like lining on their surface. These Velcro-lined filaments are thus perfectly adapted to trap the setae, or thin appendages, of diverse invertebrates, most often small crustaceans. The shape of these spicules reveals a close phylogenetic relationship between the carnivorous sponges and some filter-feeding demosponges of the order Poecilosclerida (Fig. 1d). The relationship is confirmed by molecular data and certainly thus not the result of evolutionary convergence (Fig. 43 of Hestetun

Fig. 2 Phagocytic activity analyzed by transmission electron microscopy during L. hypogea nutrition. a Archeocyte (ar) before nutrition. b Archeocyte/digestive cell (ardc) surrounding a crustacean cell (cc) $40 \mathrm{~h}$ after prey capture. At this stage, numerous phagosomes (ph) illustrate the intense phagocytic activity. c Detail of crustacean skeletal muscle (cskm) being digested by archeocyte/digestive cells (ardc). d Bacteriocyte (bc) in close contact with a sponge cell (sc) containing intravacuolar bacteria (ivb) at the beginning of the phagocytic process. e Numerous extracellular bacteria in the vicinity of a crustacean cuticle fragment (ccut). n, nucleus; ib, intracellularbacteria; psdp, pseudopod. Transmissionelectron microscopy was performed as previously described (Vacelet and Duport 2004) 


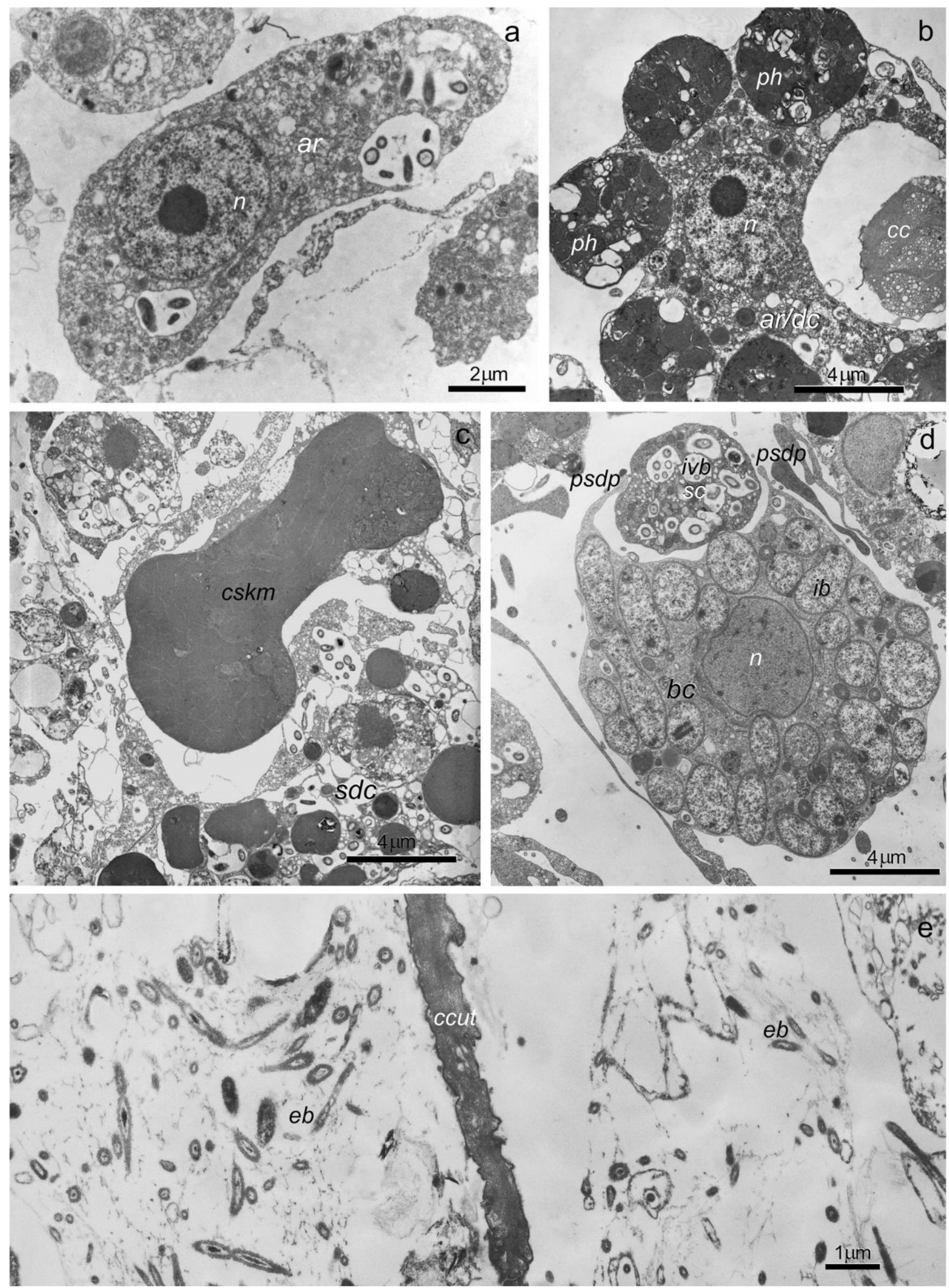


Table I Survey of hydrolases found in a differential transcriptomic analysis of unfed or fed L. hypogea. The percentage of homology with homologs in the carnivorous/filter-feeding barrier reef sponge
Amphimedon queenslandica that has been fully sequenced (Srivastava et al. 2010) is mentioned with the $e$-values of the alignments

\begin{tabular}{|c|c|c|c|c|c|}
\hline Enzyme family & & Protein name & $\begin{array}{l}\text { Regulation with } \\
\text { nutrition }\end{array}$ & $\begin{array}{l}\% \text { homology with } \\
\text { Amphimedon }\end{array}$ & $\begin{array}{l}e- \\
\text { value }\end{array}$ \\
\hline Nucleases & & Ribonuclease Oy-like & Stable & $22 \%$ & $4 e-29$ \\
\hline \multirow[t]{4}{*}{ Phosphatases } & \multirow[t]{2}{*}{ Acid phosphatases } & $\begin{array}{l}\text { Tartrate-resistant acid } \\
\text { phosphatase-like }\end{array}$ & Activated & $52 \%$ & $7 e-124$ \\
\hline & & Lysosomal acid phosphatase-like & Stable & $41 \%$ & $3 e-82$ \\
\hline & \multirow[t]{2}{*}{ Phosphodiesterases } & $\begin{array}{l}\text { Sphingomyelin } \\
\text { phosphodiesterase-like } 1\end{array}$ & Stable & $46 \%$ & $2 \mathrm{e}-158$ \\
\hline & & $\begin{array}{l}\text { Sphingomyelin } \\
\text { phosphodiesterase-like } 2\end{array}$ & Stable & $31 \%$ & $4 e-53$ \\
\hline \multirow{11}{*}{$\begin{array}{r}\text { Protease and } \\
\text { peptidases }\end{array}$} & \multirow[t]{4}{*}{ Serine-carboxypeptidases } & Cathepsin A-like & Stable & $30 \%$ & $1 \mathrm{e}-50$ \\
\hline & & Serine carboxypeptidase-like 1 & Stable & $56 \%$ & $3 e-160$ \\
\hline & & Serine carboxypeptidase-like 2 & Stable & $53 \%$ & $9 e-169$ \\
\hline & & Sérine protease-like & Stable & $44 \%$ & $7 e-133$ \\
\hline & \multirow[t]{5}{*}{ Cysteine-peptidases } & Cathepsin L-like 1 & Stable & $60 \%$ & $9 \mathrm{e}-132$ \\
\hline & & Cathepsin X/Z-like & Stable & $44 \%$ & $3 e-43$ \\
\hline & & Cathepsin B-like 1 & Stable & $46 \%$ & $5 e-93$ \\
\hline & & Cathepsin B-like 2 & Stable & $56 \%$ & $5 e-126$ \\
\hline & & Cathepsin O-like & Stable & $45 \%$ & $5 e-99$ \\
\hline & \multirow[t]{2}{*}{ Aspartic-proteases } & Lysosomal aspartic protease-like & Stable & $51 \%$ & $8 \mathrm{e}-129$ \\
\hline & & Cathepsin D-like & Stable & $55 \%$ & $3 e-156$ \\
\hline \multirow[t]{8}{*}{ Glycosidases } & \multirow[t]{3}{*}{ Galactosidases } & Galactosidase alpha-like 1 & Stable & $56 \%$ & $8 \mathrm{e}-165$ \\
\hline & & Galactosidase alpha-like 2 & Stable & $56 \%$ & $5 e-150$ \\
\hline & & Galactosidase beta-like & Stable & $49 \%$ & 0 \\
\hline & \multirow{2}{*}{ Glucosidases } & Glucosidase alpha-like & Stable & $49 \%$ & 0 \\
\hline & & Glucosidase alpha neutral-like & Stable & $68 \%$ & 0 \\
\hline & \multirow[t]{3}{*}{ Mannosidase } & Mannosidase alpha-like 1 & Stable & $49 \%$ & 0 \\
\hline & & Mannosidase alpha-like 2 & Activated & $28 \%$ & $2 \mathrm{e}-80$ \\
\hline & & Mannosidase beta-like & Stable & $47 \%$ & 0 \\
\hline \multirow[t]{3}{*}{ Sulfatases } & & Arylsulfatase A-like & Stable & $51 \%$ & 0 \\
\hline & & Arylsulfatase G-like & Activated & $39 \%$ & $1 e-56$ \\
\hline & & Arylsulfatase B-like & Stable & $71 \%$ & 0 \\
\hline Lipases & & Phospholipase A2-like & Stable & $44 \%$ & $2 \mathrm{e}-116$ \\
\hline Chitinases & & Chitinase-like & Stable & $42 \%$ & 1e-139 \\
\hline Lysozyme & & Lysozyme-like & Stable & - & - \\
\hline
\end{tabular}

Experimentally, total RNAwas isolated with RNeasy kit(QIAGEN) for eight individuals (two individuals for each condition: unfed, $15 \mathrm{~h}, 40 \mathrm{~h}$ and $216 \mathrm{~h}$ after nutrition). Libraries were constructed with a TruSeq stranded mRNA sample prep kit (Illumina, ref. RS-122-2101) according to the manufacturer instructions. Briefly, poly-A eucaryotic RNAs were purified using oligo-d(T) magnetic beads from 500ng of total RNA(toeffectively eliminate bacterial RNA). The poly-A+ RNAs were fragmented and reverse-transcribed using random hexamers, Super Script II (Life Technologies, ref. 18064-014) and actinomycin D. During the second-strand generation step, dUTP substituted dTTP. This prevents the second strand being used as a template in the final PCR amplification. Double-stranded cDNAs were adenylated at their 3' ends before ligation was performed using Illumina's indexed adapters. Ligated cDNAs were amplified following 15 cycles of PCR and PCR products were purified using AMPure XP Beads (Beckman Coulter Genomics, ref. A63881). Libraries were verified using a Bioanalyzer on a DNA1000 chip (Agilent) and quantified with a KAPALibrary quantification kit (Roche, ref. KK4824). Eight libraries were pooled in equimolar amounts and sequencing was performed on a HiSeq2000 using the paired end $2 \times 100$-nt protocol on 1 lane. This sequencing produced between 17 and 24 million passed filter clusters per library (http://www.mgx.cnrs.fr/). Artemia sequences (i.e., contaminants acquired from prey ingestion) were removed and clean reads were de novo assembled into contigs using the Trinity transcriptome assembly software by the platform MBB from Montpellier (https://mbb.univ-montp2.fr/). Sequences from L. hypogea were extracted from these databases by TBLASTN alignments with protein sequences from other model organisms on the MBB platform. The L. hypogea isolated sequences were scanned with interproscan 5 (http://www.ebi.ac.uk/Tools/pfa/iprscan5/) to verify the presence of functional or structural domains specific for each protein. In parallel, each selected sequence was used to conduct TBLASTN searches on NCBI(all databases) to rename the sequence. The best assembly contigs were used as a reference for aligning reads from the 8 different L. hypogea individuals to estimate the expression levels (Bowtie, RSEM). From thesenormalizedexpressionlevels, appropriate statistical methods(Edger,Imb) were applied toidentify genes whoseexpressionlevels vary significantly at least by a factor of 4 between conditions

et al. 2017). It is not known what the microsclere spicules do in the filter feeding as they seem randomly dispersed in the sponge tissue. The filter-feeder microscleres are not involved in providing skeletal structure, as this function is provided by larger spicules, from $150 \mu \mathrm{m}$ to some millimeters or more, called megascleres, in both filtering and carnivorous species. 
It is remarkable that in carnivorous sponges, the same spicules appear to have acquired a fundamental function in prey capture by simply changing their arrangement. The morphological similarity of cheloid microscleres of non-carnivorous and carnivorous sponges is illustrated in Fig. 1(d). The anisochelae and the placochelae of the massive filter feeders Mycale and Guitarra are randomly dispersed, while in carnivorous sponges such as Asbestopluma and Euchelipluma, the anisochelae and the placochelae form a regular lining at the filament surfaces. An intermediate stage between a filterfeeding sponge, with an aquiferous system and micro-phagic digestion and a carnivorous sponge, without the aquiferous system, is represented by the genus Chondrocladia, classified in the family Cladorhizidae along with the other carnivorous sponges. In Chondrocladia, the choanocyte chambers persist but they no longer ensure the role of filtration/digestion but rather function to inflate the spheres at the apical pole of the sponges where the prey catching spicules are arranged. There was therefore a functional inversion of the choanocyte chambers in these intermediate species. Note the main function of the choanocytes in these intermediate architectures is structural, like the role of the spicules in filter species. The spicules then have evolved from a mainly architectural role in filter/ feeder species to forming structures exclusively involved in prey capture in the carnivorous species. Finally, in most strictly carnivorous sponges, the choanocyte chambers have completely disappeared, leading to a total reorganization of the body plan and digestion system.

\section{Functional consequences of the carnivorous diet}

Filtering and carnivorous sponges developed different strategies for nutrition because the food for the latter species is much larger, up to $8 \mathrm{~mm}$, whereas filtered particles are in the $1 \mathrm{~nm}$ to $2 \mu \mathrm{m}$ range. These different strategies do not imply differences in phagocyte size (around $10 \mu \mathrm{m}$ ). Another major difference is that nutritive particles are delivered to the cells via the inhalant channels in the filtering species, whereas in the carnivores, which do not have any of these structures, it is the phagocytic cells that migrate towards the food after capture of a prey (Martinand-Mari et al. 2012). Finally, in filtering species, there is no major morphological change associated with nutrition, as it is practically continuous, although there can be occasional breaks in filtration with orifice closures during reorganization of the aquiferous system. In L. hypogea on the other hand, where food intake is discontinuous and dependent on the capture of a prey, which can arrive months apart, there are dramatic morphologic rearrangements during a digestion cycle during which the sponge changes form and returns to the initial state (Fig. 3a-d). Our lab is currently conducting an analysis of the differential expression of the molecular actors that control this unique form of shape homeostasis in carnivorous sponges. Extending the results obtained in Lycopodina to the deepwater carnivorous sponges suggests this cyclical mode of nutrition could be an adaptation to the oligotrophic environments of the abyssal conditions. This hypothesis is consistent with the fact that indeed hexactinellids, which have the most efficient filtration/nutrition system of any sponges, have difficulty reaching a depth of $6770 \mathrm{~m}$, whereas carnivorous species are found below $8000 \mathrm{~m}$, including one at $8840 \mathrm{~m}$. The tendency towards carnivorous behavior and macro-prey in deep-sea species has also been described in other invertebrate groups. Thus, large copepods were found in the digestive tract of abyssal sea squirts (e.g., in Octanemidae, Ascidiidae and in the Sorberacea class) (Monniot and Monniot 1975, 1991). These tunicates likely switch between filtering and carnivorousness and thus their evolution was less drastic and they only have a small anatomical modification of the branchial sac without any major reorganization of the overall body plan.

Conversely, carnivorous sponges are concrete proof that a radical functional transition is possible between a system of nutrition/digestion by filtration and a one of feeding by capture of prey, with total loss of the filtration system. This transition was accompanied by a profound change in the overall organizational plan and especially of the digestion system. In L. hypogea, this morpho-functional reorganization is directly associated with the acquisition of an axial polarity of the whole organism (polarity being defined as a structure that is different at one pole with respect to the opposite one) that, equally remarkably, resembles the apico-basal polarity at the cellular level of the epithelial digestive system in mammals (Fig. 3e, f).

Digestion of large prey necessitates a panel of digestive enzymes and we found there is a remarkable diversity of enzyme equipment in L. hypogea. All the main families of lysosomal enzymes are present in the L. hypogea transcriptome, i.e., the nucleases, phosphatases, proteases, peptidases, glycosidases, sulfatases and lipases (Table 1). Most of these enzymes are expressed at a constant level throughout the digestion cycle. However, some, including tartrate-resistant acid phosphatase type 5-like, mannosidase alpha-2-like and arylsulfatase G-like, are induced by a nutritional stimulus (Table 1). These preliminary data, however, allow us to initially say that the mechanisms involved in intracellular digestion in L. hypogea are at least partly subject to physiological regulation and also that these mechanisms are as complex biochemically as those of higher vertebrates. Finally, the presence of lysozyme and of a chitinase (Table 1) suggests there is a preliminary extracellular digestion in carnivorous sponges to degrade the prey, which are almost exclusively small crustaceans. Various chitinases and other bacterial enzymes must also contribute to this degradation, as suggested by Vacelet and Duport (2004). Taken together, these considerations suggest that the nutrition/digestion strategy of the whole organism in carnivorous sponges is phenomenologically similar to that 


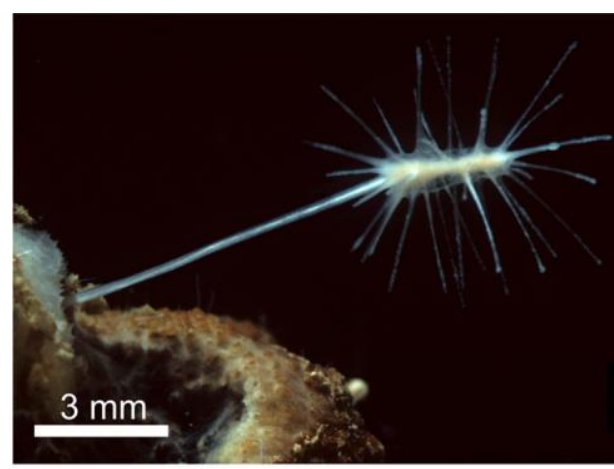

a
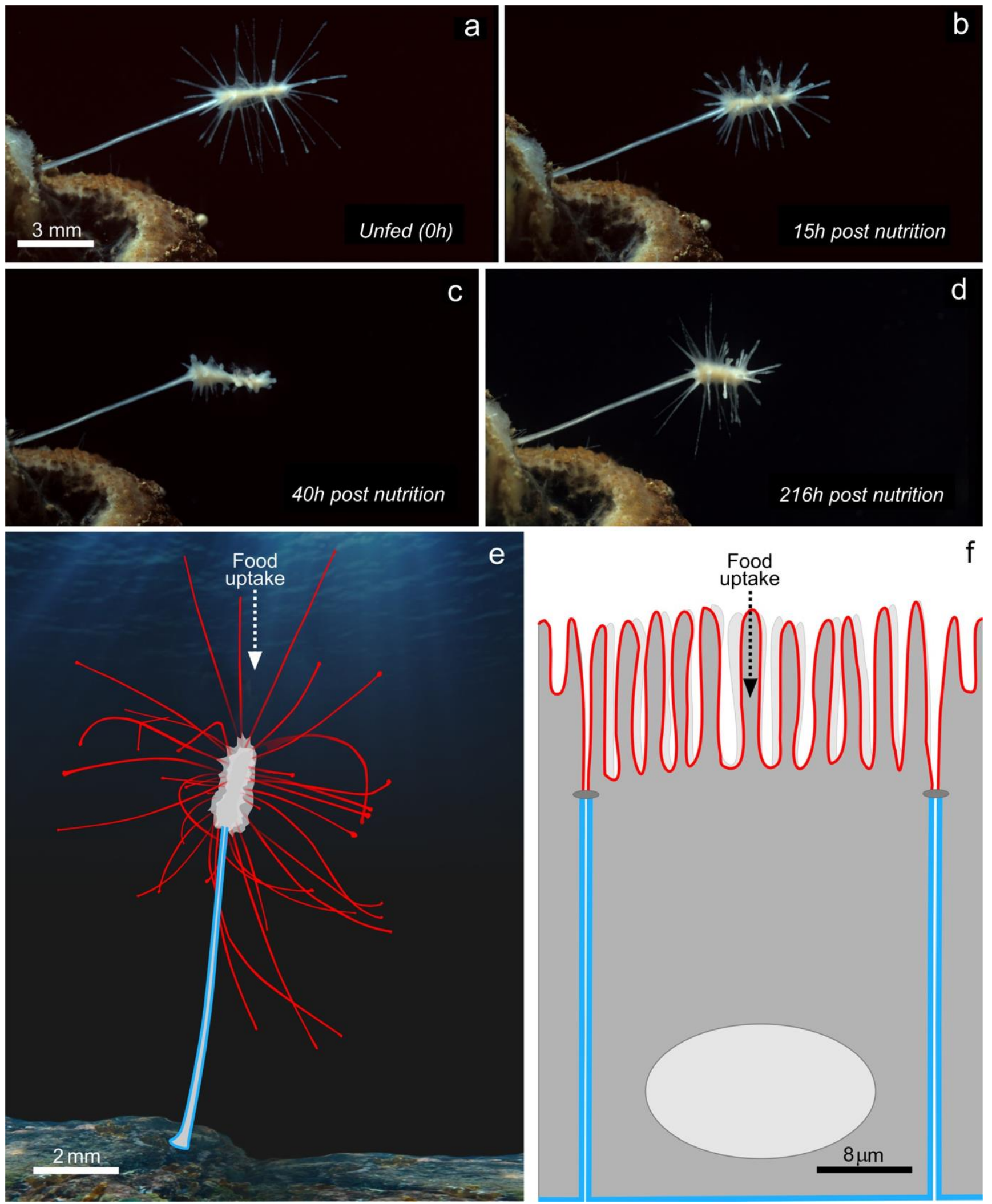

Fig. 3 Nutrition/digestion features associated with carnivorous diet. a-d Morphological changes of Lycopodina hypogea during a digestion cycle L. hypogea and mammalian digestive cell. Schematic representation of apico-basal polarity of carnivorous sponge (e) and a digestive epithelial cell (f). The red lines represent the apical pole and the blue line the at the indicated times after introduction of prey. The long filaments of the apical region regress completely $40 \mathrm{~h}$ post-nutrition (c) to reform at the end of the digestive cycle (d). e and f Functional analogy between 
of the cells of the digestive tube of most bilaterians. From bacteria to higher vertebrates, the regulation of the composition of the proteins at the membrane and especially their asymmetric distribution, has played a determining role in the morpho-functional diversification of prokaryotic and eukaryotic cells. For example, in the bacterium Caulobacter crescentus, the polarized distribution of the flagellum anchor protein allows differentiation of an individual mother cell into animmobile pedunculated cell plus another flagellated mobile cell (Gober et al. 1991). In these bacteria, it is the asymmetric membrane-protein distribution that allows genuine social behavior in the colony and that optimizes the use of nutrient resources. In the absorptive intestinal cells of vertebrates (known as enterocytes), an asymmetry of the biochemical composition of apical and basolateral membrane domains leads to a morphological differentiation of the apical domain into a specialized brush border. Here, polarity is at the origin of a functional differentiation of the two membrane domains and an increase of the exchange surface of the apical membrane domain with the lumen of the digestive tract. By analogy, polarity is also found in the difference in cell composition and global shape between the basal and apical regions of $L$. hypogea. This difference results in a functional differentiation of the whole organism and the establishment of many long filaments in the apical region. These filaments increase the interaction surface of the prey capture system with the medium, thus increasing and optimizing nutrition by vectorial transport of nutrients. This efficient directional transport is illustrated in a cell or organism, respectively, in Fig. 3 (e, f). It is likely that it is this efficient nutritive system that has allowed carnivorous sponges to colonize the extreme depths of the world's oceans.

\section{Involvement of microbiota in the carnivorous diet}

Marine filtering sponges harbor a complex and diverse community of microbes and the carnivorous L. hypogea is no exception as around 800 operational taxonomic units of bacterial and archaeal phyla have been documented in this model carnivore (Dupont et al. 2013, 2014). These bacteria likely help with the digestion of prey as they include strains with chitinolytic activity. A recent study shows that similar microbial communities are present in other carnivorous sponges, Chondrocladia grandis and Cladorhiza oxeata and that there are bacterial communities that are specific to either sponge but also that certain bacterial taxa are enriched in distinct anatomical regions. For example, bacteria of the genera Colwellia and Reichenbachiella are found mainly in the capture spheres (apical position) while the bacteria of the genera Robiginitomaculum, Maritimimonas, Granulosicoccus, Mycobacterium, Anderseniella and Nitrospira are concentrated in the peduncle (basal position) (Verhoeven and Dufour 2017). Digestion therefore likely relies on both bacterial and lysosomal enzymes. In L. hypogea, the prey is literally engulfed in a few hours by archeocytes that have differentiated into digestive cells and by bacteriocytes that have numerous cytoplasmic bacteria (Fig. $2 b-d$ ). The exact species of bacteria inside and outside the bacteriocytes (Fig. $2 \mathrm{~d}$, e) have not yet been identified, but transmission electron microscopy data strongly suggest their involvement in the extracellular and intracellular digestion process (Fig. 2). Thus, the bacteria cooperate with the digestive cells and contribute to the total degradation of the prey. The entire autolytic/ phagocytic process lasts between 8 and 10 days for larger prey in the 8 -mm range. Interestingly, the bacterial communities associated with carnivorous sponges are not very different from those of filtering sponges. There are a few examples of bacterial host specificity. For example, methanotrophic bacteria are only found in the carnivorous Cladorhiza methanophila (Hestetun et al. 2016). Thus, the acquisition of a strict carnivorous diet was not accompanied by a significant related modification of the diversity of associated bacterial communities; the bacteria in filtering sponges are equally important for the efficient digestion of prey in carnivorous sponges. There is equivalence for host lysosomal enzymes also, which have a comparable diversity and primary structure in carnivorous and filter/feeder sponges (Table 1). In summary, most of the biochemical and microbiological actors already present in classical models in sponge biology also contribute to the digestion processes of carnivorous sponges. However, in some cases (e.g., the secreted enzyme lysosyme that is present in L. hypogea transcriptome but not in the genome of the filter-feeding sponge A. queenslandica, see Table 1), we can suppose that subtle biochemical innovations have occurred during the filter feeder/carnivorous diet transition.

\section{Conclusion}

Several plant lineages have adapted to include active predation into their modus operandi but none have abandoned their ancestral strategy of photosynthesis. By contrast, in sponges, the major evolutionary transition to a new axial polarity of the digestion system that led to the acquisition of carnivory enabled some sponges to relinquish passive filter feeding. Indeed, in organisms that have a digestive cavity or an aquiferous system as in filtering sponges, it is the food that is brought to the digestive system while it is the opposite in carnivorous sponges. This inversion of morpho-functional polarity was accomplished by a remarkable organizational plasticity in the basic sponge body plan. Identifying the molecular and cellular actors involved in this plasticity could help us better understand the evolutionary history and beginnings of early metazoans. One theory, still debated, is that sponges and choanoflagellates that both capture nutritive 
particles with an apical sieve might have evolved directly from a unicellular common ancestor. More generally, the question now is how the sponges have evolved from this common ancestor to multicellular filtering forms. Similarly, the transition from the sponge phylum to other metazoans is complex and still uncertain. One side-branch of this evolution was the transition of sponges to the carnivorous diet, which evolved just one time. The sponges and cnidarian lineages diverged 600 million years ago, whereas the split between filtering and carnivorous sponges was more recent and occurred only in the Poecilosclerida order of the Demospongiae. Since it is now clearly established that Porifera are the most basal metazoans (Simion et al. 2017; Pett et al. 2019), we can therefore postulate that three or four sponge phyla derived from the Urmetazoa and kept the filter-feeder organization and exclusively intracellular phagocytosis, while the other Metazoa lost the canal system and choanocyte chamber. However, it was clearly a major evolutionary task to go from a sponge to a Cnidaria or other metazoans. Indeed, as stated by Cavalier-Smith: Bit is selectively immensely harder for organisms that feed by swallowing others or bits of them (a purely eukaryotic propensity) to switch from intracellular phagocytosis, as in amoebae or ciliates, to eating with a multicellular mouth and gut, whose cells have novel functions and structures absent in their unicellular ancestors. Animal feeding is effective only if novel cell types cooperate at a higher organizational level^ (CavalierSmith 2017). The complete loss of filter-feeding apparatus in sponges and its replacement by another type of organization leading to carnivory is a rare example of such a major transition in evolution. Therefore, further cellular and molecular studies of carnivorous sponges could improve our understanding of the evolutionary innovations that have led to the formation of a stomodeum, a mouth and a coelenteron in cnidarians and to the development of a coelom with lengthening of the stomodeum and formation of the digestive tract in all other metazoans.

Acknowledgments We thank Laurence Meslin (CNRS, BPlateforme Communication Scientifique Visuelle - ISEM ${ }^{\wedge}$ ), for the drawing and elaborating the figures. For the transcriptomic data, we benefited from the Montpellier Bioinformatics Biodiversity platform supported by the LabEx CeMEB, an ANR BInvestissements d'avenir^ program (ANR10-LABX-04-01).

\section{Compliance with ethical statements}

Conflict of interest The authors declare that they have no conflict of interest.

Ethical approval All applicable international, national and/or institutional guidelines for the care and use of animals were followed.

\section{References}

Bergquist PR (1978) Sponges. Hutchinson, London \& University of California Press, Berkeley \& Los Angeles, pp 1-268
Cavalcanti FF, Klautau M (2011) Solenoid: a new aquiferous system to Porifera. Zoomorphology 130:255-260. https://doi.org/10.1007/ s00435-011-0139-7

Cavalier-Smith T (2017) Origin of animal multicellularity: precursors, causes, consequences-the choanoflagellate/sponge transition, neurogenesis and the Cambrian explosion. Philos Trans R Soc B 372:20150476. https://doi.org/10.1098/rstb.2015.0476

Diaz J (1979) Variations, différenciations et fonctions des catégories cellulaires de la démosponge d'eaux saumâtres, Suberites massa Nardo, au cours du cycle biologique annuel et dans des conditions expérimentales. Docteur d'Etat Mention Sciences, Université des sciences et techniques du Languedoc

Dupont S, Corre E, Li Yet al (2013) First insights into the microbiome of a carnivorous sponge. FEMS Microbiol Ecol 86:520-531. https:// doi.org/10.1111/1574-6941.12178

Dupont S, Carre-Mlouka A, Domart-Coulon I et al (2014) Exploring cultivable Bacteria from the prokaryotic community associated with the carnivorous sponge Asbestopluma hypogea. FEMS Microbiol Ecol 88:160-174. https://doi.org/10.1111/1574-6941.12279

Fukushima K, Fang X, Alvarez-Ponce D et al (2017) Genome of the pitcher plant Cephalotus reveals genetic changes associated with carnivory. Nat Ecol Evolut 1:0059. https://doi.org/10.1038/s41559016-0059

Funayama N (2013) The stem cell system in demosponges: suggested involvement of two types of cells: archeocytes (active stem cells) and choanocytes (food-entrapping flagellated cells). Dev Genes Evol 223:23-38. https://doi.org/10.1007/s00427-012-0417-5

Gober JW, Alley MR, Shapiro L (1991) Positional information during Caulobacter cell differentiation. Curr Opin Genet Dev 1:324-329

Hahn-Keser B, Stockem W (1998) Intracellular pathways and degradation of endosomal contents in basal epithelial cells of freshwater sponges (Porifera, Spongillidae). Zoomorphology 117:223-236. https://doi.org/10.1007/s004350050047

Hestetun JT, Dahle H, Jørgensen SL et al (2016) The microbiome and occurrence of methanotrophy in carnivorous sponges. Front Microbiol 7:1781. https://doi.org/10.3389/fmicb.2016.01781

Hestetun JT, Tompkins-Macdonald G, Rapp HT (2017) A review of carnivorous sponges (Porifera: Cladorhizidae) from the boreal North Atlantic and Arctic. Zool J Linnean Soc 181:1-69. https:// doi.org/10.1093/zoolinnean/zlw022

Krasko A, Gamulin V, Seack J et al (1997) Cathepsin, a major protease of the marine sponge Geodiacydonium: purification of the enzyme and molecular cloning of cDNA. Mol Mar Biol Biotechnol 6:296-307

Leys SP, Mackie GO, Reiswig HM (2007) The biology of glass sponges. Adv Mar Biol 52:1-145. https://doi.org/10.1016/S0065-2881(06) 52001-2

Martinand-Mari C, Vacelet J, Nickel M et al (2012) Cell death and renewal during prey capture and digestion in the carnivorous sponge Asbestopluma hypogea (Porifera: Poecilosclerida). J Exp Biol 215: 3937-3943. https://doi.org/10.1242/jeb.072371

Monniot C, Monniot F (1975) Abyssal tunicates: an ecological paradox. Ann Inst océanogr 51(1):99-129

Monniot C, Monniot F (1991) Découverte d'une nouvelle lignée évolutive chez les ascidies de grande profondeur : une Ascidiidae carnivore. C R Acad Sci Paris III:383-388

Perez T, Ruiz C (2018) Description of the first Caribbean Oscarellidae (Porifera: Homoscleromorpha).Zootaxa 4369:501-514. https://doi. org/10.11646/zootaxa.4369.4.3

Pett W, Adamski M, Adamska M et al (2019) The role of homology and orthology in the phylogenomic analysis of metazoan gene content. Mol Biol Evol. https://doi.org/10.1093/molbev/msz013

Riesgo A, Taylor C, Leys SP (2007) Reproduction in a carnivorous sponge: the significance of the absence of an aquiferous system to the sponge body plan. Evol Dev 9:618-631. https://doi.org/10.1111/ j.1525-142X.2007.00200.x 
Simion P, Philippe H, Baurain D et al (2017) A large and consistent phylogenomic dataset supports sponges as the sister group to all other animals. Curr Biol 27:958-967. https://doi.org/10.1016/j.cub. 2017.02.031

Srivastava M, Simakov O, Chapman J et al (2010) The Amphimedon queenslandica genome and the evolution of animal complexity. Nature 466:720-726. https://doi.org/10.1038/nature09201

Vacelet J, Boury-Esnault N (1995) Carnivorous sponges. Nature 373(6512):333-335

Vacelet J, Duport E (2004) Prey capture and digestion in the carnivorous sponge Asbestopluma hypogea (Porifera: Demospongiae). Zoomorphology 123:179-190. https://doi.org/10.1007/s00435004-0100-0

Verhoeven JTP, Dufour SC (2017) Microbiomes of the Arctic carnivorous sponges Chondrocladia grandis and Cladorhiza oxeata suggest a specific, but differential involvement of bacterial associates. Arctic Sci 4:186-204. https://doi.org/10.1139/as-2017-0015

Willenz P (1980) Kinetic and morphological aspect of particle ingestion by the freshwater sponge Ephydatia fluviatilis L. In: Smith DC, Tiffon Y (eds) Nutrition in the lower Metazoa. Pergamon Press, Oxford \& New York 